\title{
Parental smoking and childhood asthma: longitudinal and case-control studies
}

\author{
David P Strachan, Derek G Cook
}

\begin{abstract}
Background-The relation of parental smoking to wheezing and asthma occurring after the first year of life was assessed by a systematic quantitative review of case-control and longitudinal studies, complementing earlier reviews of cross sectional surveys and wheezing in early childhood.
\end{abstract}

Methods-Fifty one relevant publications were identified after consideration of 1593 abstracts selected by electronic search of the Embase and Medline databases using keywords relevant to passive smoking in children. The search was completed in April 1997 and identified six studies of asthma incidence, seven of prognosis, 22 case-control studies, and 10 case series addressing disease severity.

Results-Maternal smoking was associated with an increased incidence of wheezing illness up to age 6 (pooled odds ratio $1.31,95 \%$ CI 1.22 to 1.41 ), but less strongly thereafter $(1.13,95 \%$ CI 1.04 to 1.22). The long term prognosis of early wheezing illness was better if the mother smoked. The pooled odds ratio for asthma prevalence from 14 case-control studies was $1.37(95 \%$ CI 1.15 to 1.64$)$ if either parent smoked. Four studies suggest that parental smoking is more strongly associated with wheezing among non-atopic children. Indicators of disease severity including symptom scores, attack frequency, medication use, hospital attendance, and life threatening bronchospasm were in general positively related to household smoke exposure.

Conclusions-The excess incidence of wheezing in smoking households appears to be largely non-atopic "wheezy bronchitis" with a relatively benign prognosis, but among children with established asthma, parental smoking is associated with more severe disease. This apparent paradox may be reconciled if environmental tobacco smoke is considered a co-factor provoking wheezing attacks, rather than a cause of the underlying asthmatic tendency.

(Thorax 1998;53:204-212)

Keywords: parental smoking; asthma; children
Previous reviews in this series have shown that parental smoking is associated with an increased incidence of acute lower respiratory illnesses, including wheezing illnesses, in the first one or two years of life, ${ }^{1}$ but does not increase the risk of sensitisation to common aeroallergens, ${ }^{2}$ an important risk factor for asthma of later onset. Prevalence surveys of school children suggest that wheeze and diagnosed asthma are more common among children of smoking parents, with a greater increase in risk for more severe definitions of wheeze. ${ }^{3}$ This paper reviews the evidence from longitudinal and case-control studies of wheezing illness concerning the effect of parental smoking on the incidence, prognosis, prevalence, and severity of childhood asthma.

\section{Methods}

Published papers, letters, and review articles were selected by an electronic search of the Embase and Medline databases using the search strategy described in detail elsewhere. ${ }^{1}$ Briefly, all passive smoking references were selected by the MESH heading tobacco smoke pollution and/or textword combinations (\{passive, second-hand, second hand, involuntary, parent ${ }^{\star}$, maternal, mother*, paternal, father* or household $\}$ and $\left\{\right.$ smok $^{\star}$, tobacco $^{\star}$ or cigarette $\left.^{\star}\right\}$ ). Papers were then restricted to children by relevant textwords or by the age group as specified in the title or abstract. This search, completed in April 1997, yielded 3625 references of which 1593 contained keywords relevant to respiratory or allergic disease. Papers relating to asthma or wheezing illness were selected by review of the on-line abstracts. Studies of wheezing illness in the first two years of life ${ }^{1}$ and cross sectional studies of asthma and wheeze $\mathrm{e}^{3}$ have been reviewed earlier in this series.

In this paper we have included longitudinal and case-control studies of asthma or wheeze occurring after infancy and case series of asthmatic patients among whom parental smoking was related to disease severity. Forty nine relevant papers were identified from the literature search and a further two were identified by personal knowledge. These 51 papers related to 10 longitudinal studies, 22 case-control studies, and 10 uncontrolled case series. 
Table 1 Design, sample size and recruitment criteria for studies included in this overview

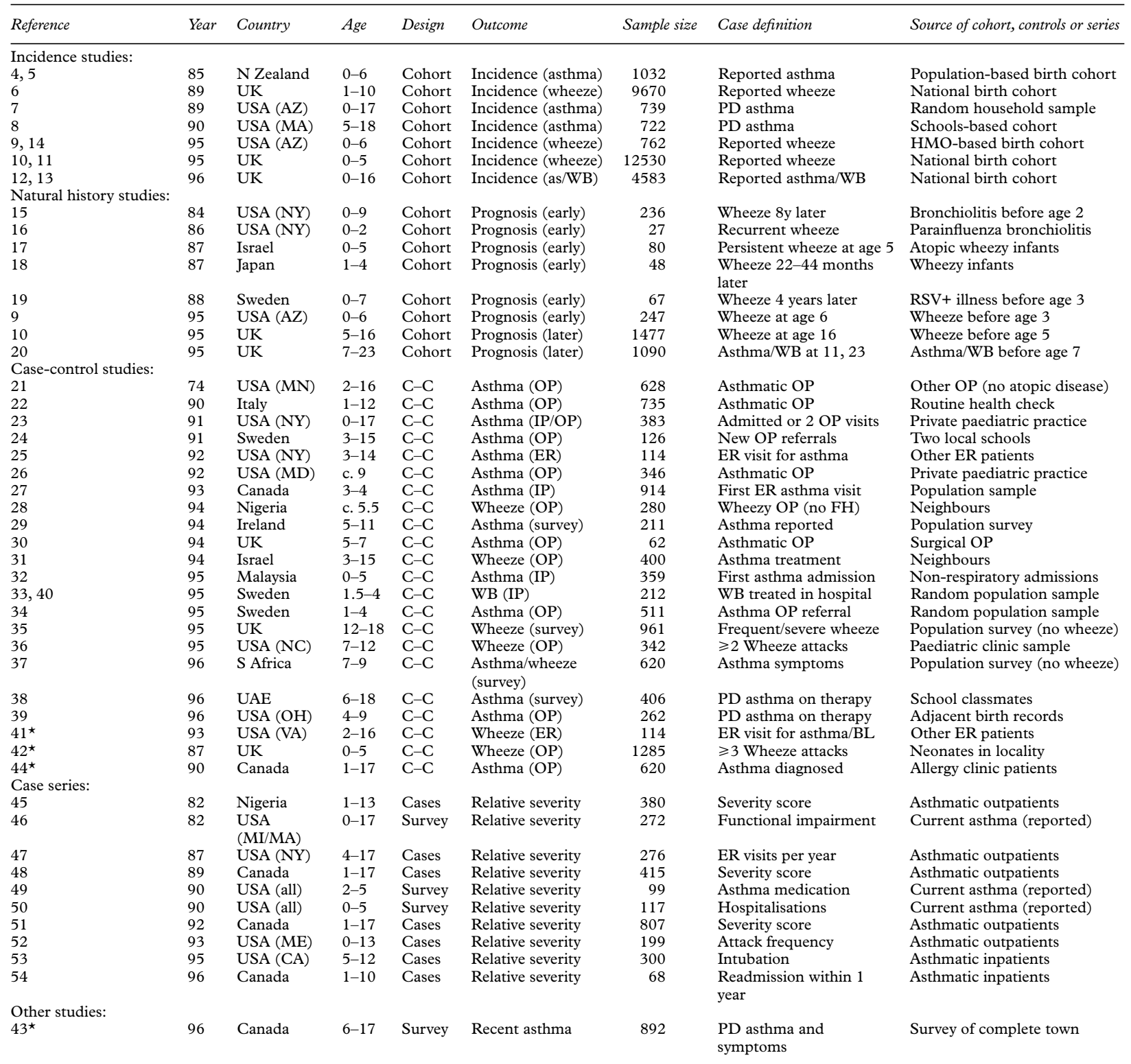

$\mathrm{PD}=$ physician diagnosed $\mathrm{WB}=$ wheezy bronchitis $\mathrm{BL}=$ bronchiolitis $\mathrm{RSV}=$ respiratory syncytial virus; $\mathrm{ER}=$ emergency room; OP $=$ outpatients; $\mathrm{IP}=$ inpatients; $\mathrm{FH}=$ family history. ${ }^{\star}$ Not included in the meta-analysis of case-control studies (table 3 ) but discussed in the text.

The approach to data extraction and statistical analysis followed that of earlier reviews in this series. ${ }^{1}$ Due to the small number of longitudinal studies identified, odds ratios relating parental smoking to incidence and prognosis of wheezing illness were pooled using weights inversely proportional to their variance (the "fixed effect" assumption). Odds ratios from the larger number of case-control studies were pooled using a "random effects" model, as described in detail elsewhere. ${ }^{1}$ No quantitative meta-analysis was possible for studies of disease severity.

\section{Results}

LONGITUDINAL STUDIES: INCIDENCE

Ten papers ${ }^{4-13}$ relating to six longitudinal studies were identified which report upon the incidence of wheezing illnesses after the first two years of life in relation to parental smoking habits (table 1). Five papers are concerned mainly with preschool wheezing, ${ }^{45-11}$ two focus on wheeze developing for the first time during the school years, ${ }^{812}$ and three include both early and later childhood. ${ }^{6713}$ These studies complement the larger number of studies addressing incidence of wheezing illness in infancy reviewed previously. ${ }^{1}$ The results are summarised in table 2 and fig 1 , and are discussed briefly below.

Investigators in Tucson, Arizona followed up a birth cohort registered with a health maintenance organisation. ${ }^{9}$ Among 762 subjects followed through the first three years of life and also at the age of six, 403 had no history of wheezing, 147 wheezed by the age of three years but not at age six ("transient early wheezing"), 112 developed wheezing after the age of three ("late onset wheezing"), and 100 wheezed before the age of three and at six years of age ("persistent wheezing"). The incidence of wheezing before the age of three (transient 


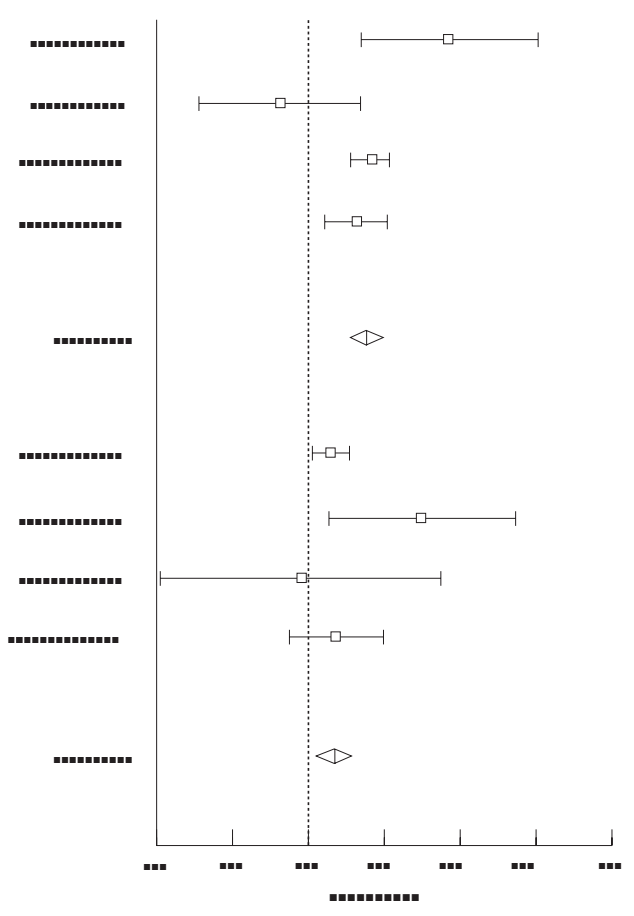

Figure 1 Odds ratios and 95\% confidence intervals for the effect of maternal smoking on the incidence of asthma or wheezing throughout childhood, cohort studies. The upper part lists studies which include the first year of life (exact incidence period shown on left) contributing to the pooled odds ratio (1) derived by the "fixed effect" method, and the lower part gives studies which exclude the first year of life (exact incidence period shown on left) contributing to pooled odds ratio (2) derived by the "fixed effect" method.

and persistent wheezers combined) was doubled if the mother smoked $\geqslant 10$ cigarettes per day. The incidence of later onset wheezing was less strongly associated with maternal smoking (table 2). These associations are virtually unchanged after adjustment for sex, ethnicity, eczema, non-infective rhinitis, and maternal asthma. ${ }^{9}$ For comparison with other studies of early childhood wheezing, the cumulative incidence of wheezing by the age of six is also presented in table 2. Although these incidence data are presented and analysed by maternal smoking habit, another publication from the same cohort study has suggested that, for children in day care, smoking by the caregiver may be of greater importance as a determinant of the frequency of wheezing illnesses in the third year of life. ${ }^{14}$

In a similar population-based birth cohort study in Christchurch, New Zealand, 1032 children were followed at annual intervals up to the age six years. ${ }^{45}$ In contrast to other studies, the cumulative incidence of asthma symptoms, as reported by parents, was reduced if the mother smoked and increased if the father smoked. The incidence was also lower if both parents smoked than if neither smoked. Analyses using medical consultations for asthma ${ }^{5}$ and frequency of asthma attacks in the first six years of life ${ }^{4}$ showed a similar pattern.

The incidence of all forms of wheezing in the nationwide British 1970 birth cohort was ascertained retrospectively by parental recall at the age of five years. The direction and strength of dose-response relationships with smoking in pregnancy (shown in table 2) and when the child was aged five years are almost identical. ${ }^{10}$ The cumulative incidence of wheezing among children of smoking mothers was increased and little changed by adjustment for sex, birth weight, and breast feeding. ${ }^{10}$ There was also an increased incidence of asthma by the age of five years if the mother smoked. ${ }^{11}$ Another study based on the same birth cohort explicitly excluded wheezing in the first year of life and included information from follow up studies at ages five and 10 years. ${ }^{6}$ Maternal smoking was associated with wheezing labelled as wheezy bronchitis (incidence ratio $1.44,95 \%$ CI 1.24 to 1.68 ) but not with wheezing labelled as asthma (incidence ratio $0.96,95 \%$ CI 0.77 to 1.22). Most of the published analyses relate only to the former category, which accounts for only $38 \%$ of all incident wheezing. In the absence of maternal smoking, smoking by the father was not associated with an increased risk of wheezy bronchitis (incidence ratio 0.99, $95 \%$ CI 0.76 to 1.29 ) and was not assessed for other forms of wheezing.

An earlier national British birth cohort born in $1958^{12} 13$ contributed information both on early and later incidence of wheezing illness. As in the 1970 cohort, ${ }^{10}$ early wheezing illnesses were ascertained retrospectively, in this case at the age of seven, and were more common if the mother smoked in pregnancy. This association was independent of multiple other risk factors. ${ }^{12}$ Among 4583 children without a history of asthma or wheezy bronchitis reported by parents at seven years of age, the incidence from age seven to 16 differed little according to whether the mother had smoked during pregnancy, but there were weak nonsignificant positive associations with smoking by the mother and by the father at the 16 year follow up (table 2).

A smaller longitudinal study in Boston, Massachusetts $^{8}$ also found little relationship between parental smoking and the incidence of asthma over a mean of nine years annual follow up among 722 children with no history of asthma on entry to the study at age 5-9 years (table 2). In another American cohort doctordiagnosed asthma, but not other wheezing illnesses, was ascertained at one to two yearly intervals among a random sample of households in Tucson, Arizona. ${ }^{7}$ Maternal smoking was associated with an increased risk of asthma, whereas smoking by the father was not (table 2). The effect of maternal smoking was stronger among less educated families, although this statistical interaction is not significant.

In quantitative meta-analyses of studies of early and later incidence of asthma and wheezing illness, the association with maternal smoking is significantly stronger for incidence in the first 5-7 years of life ${ }^{491012}$ (four studies: pooled odds ratio $1.31,95 \%$ CI 1.22 to $1.41, \chi^{2}$ for heterogeneity 8.58, $\mathrm{p}=0.035$ ) than for incidence during the school years ${ }^{812}$ or throughout childhood excluding infancy ${ }^{6} 7$ (four studies: pooled odds ratio $1.13,95 \% \mathrm{CI}$ 1.04 to $1.22, \chi^{2}$ for heterogeneity $3.71, \mathrm{p}=$ 0.29). 
Table 2 Incidence and prognosis of asthma or wheeze by parental smoking

\begin{tabular}{|c|c|c|c|c|c|c|c|c|}
\hline Reference & \multicolumn{2}{|c|}{ Age at start/end } & Duration of follow up & Smoking exposure & Outcome & Cases & Non-cases & Odds ratio $(95 \% \mathrm{CI})$ \\
\hline \multicolumn{9}{|c|}{ Incidence studies: } \\
\hline 9 & 0 & 3 & & Mother $\geqslant 10 \mathrm{cigs} /$ day & Wheeze & 247 & 515 & $2.07(1.34$ to 3.19$)$ \\
\hline 9 & 3 & 6 & & Mother $\geqslant 10 \mathrm{cigs} /$ day & Wheeze & 112 & 403 & $1.59(0.89$ to 2.84$)$ \\
\hline 9 & 0 & 6 & & Mother $\geqslant 10$ cigs $/$ day & Wheeze & 359 & 403 & $1.91(1.28 \text { to } 2.86)^{\star}$ \\
\hline \multirow[t]{2}{*}{4} & 0 & 6 & & Mother smoking & Asthma & 141 & 891 & $0.88(0.61 \text { to } 1.27)^{\star}$ \\
\hline & & & & Father smoking & Asthma & 141 & 891 & $1.27(0.89$ to 1.81$)$ \\
\hline 10 & 0 & 5 & & Mother in pregnancy & Wheeze & 2616 & 9914 & $1.34(1.22 \text { to } 1.45)^{\star}$ \\
\hline 6 & 1 & 10 & & Mother smoking at any age & Wheeze & 1662 & 8016 & $1.11(1.02 \text { to } 1.21)^{\star}$ \\
\hline \multirow[t]{2}{*}{7} & $<5$ & $?$ & 12 years & Mother $\geqslant 10 \mathrm{cigs} /$ day & Asthma & 86 & 653 & $1.68(1.10 \text { to } 2.58)^{\star}$ \\
\hline & & & & Father $\geqslant 10$ cigs $/$ day & Asthma & 78 & 622 & $1.06(0.67$ to 1.69$)$ \\
\hline \multirow[t]{2}{*}{8} & $5-9$ & ? & 9 years & Mother smoking & Asthma & 43 & 679 & $0.97(0.51 \text { to } 1.84)^{\star}$ \\
\hline & & & & Father smoking & Asthma & 43 & 679 & $0.91(0.49$ to 1.69$)$ \\
\hline 12 & 0 & 7 & & Mother in pregnancy & Asthma or WB & 1026 & 4583 & $1.25(1.08 \text { to } 1.44)^{\star}$ \\
\hline \multirow[t]{3}{*}{12} & 7 & 16 & & Mother in pregnancy & Asthma or WB & 368 & 4215 & $0.99(0.78$ to 1.25$)$ \\
\hline & & & & Mother at 16 y follow up & Asthma or WB & 368 & 4215 & $1.14(0.92 \text { to } 1.41)^{\star}$ \\
\hline & & & & Father at 16 y follow up & Asthma or WB & 368 & 4215 & $1.10(0.88$ to 1.36$)$ \\
\hline \multicolumn{9}{|c|}{ Natural history studies: } \\
\hline 15 & $<2$ & 8 & & Either parent smoking & Persistent wheeze & 26 & 33 & $1.45(0.45 \text { to } 4.70)^{\star}$ \\
\hline 17 & $<2$ & 5 & & Either parent smoking & Persistent wheeze & 26 & 54 & $3.10(1.08 \text { to } 8.91)^{\star}$ \\
\hline 18 & $<3$ & ? & $22-44$ months & Household members smoke & Recent wheeze & 18 & 22 & $11.80(1.32 \text { to } 105)^{\star}$ \\
\hline 19 & $<3$ & ? & 4 years & Either parent smoking & Recent wheeze & 22 & 45 & $0.80(0.28 \text { to } 2.27)^{\star}$ \\
\hline 9 & $<3$ & 6 & & Mother $\geqslant 10$ cigs/day & Recent wheeze & 100 & 147 & $0.99(0.53 \text { to } 1.86)^{\star}$ \\
\hline 10 & $<5$ & 16 & & Mother in pregnancy & Wheeze past year & 218 & 1259 & $0.86(0.64 \text { to } 1.15)^{\star}$ \\
\hline 20 & $<7$ & 11 & & Mother in pregnancy & As/WB past year & 203 & 887 & $0.56(0.40 \text { to } 0.78)^{\star}$ \\
\hline 20 & $<7$ & 23 & & Mother in pregnancy & As/WB past year & 101 & 989 & $0.70(0.50$ to 0.98$)$ \\
\hline
\end{tabular}

${ }^{\star}$ Odds ratios used in meta-analyses (see text). WB=wheezy bronchitis.

\section{PROGNOSIS}

Tables 1 and 2 summarise eight studies ${ }^{9} 10 \quad 15-20$ relating parental smoking to the natural history of wheezing illness in childhood. Three studies ${ }^{917} 18$ have analysed the short term prognosis of all forms of wheezing from infancy to school age. Two studies report specifically on the prognosis of wheezing following respiratory syncytial virus infection ${ }^{19}$ or bronchiolitis in infancy. ${ }^{15}$ The results of these five studies are all consistent with parental smoking being associated with a small increased risk of wheeze persisting after early childhood (pooled odds ratio $1.35,95 \%$ CI 0.87 to $2.08, \chi^{2}$ for heterogeneity $8.07, \mathrm{p}=0.089$ ).

The short term prognosis of bronchiolitis due to parainfluenza virus infection in infancy was evaluated among 27 children after approximately three years (range 8-51 months). ${ }^{16}$ The mean number of subsequent wheezing episodes was significantly higher $(p<0.05)$ in children whose parents smoked (3.0 versus 1.6 episodes), but the findings cannot be expressed in the form of an odds ratio for direct comparison with other prognostic studies.

The opposite effect of parental smoking on prognosis emerges from longer term follow up in two British birth cohort studies. ${ }^{10}{ }^{20}$ Among children from the 1958 cohort who had a history of asthma or wheezy bronchitis by the age of seven, maternal smoking was associated with a significantly reduced risk of asthma or wheezy bronchitis at ages 11 and $23,{ }^{20}$ despite the tendency of children of smoking parents to become active smokers, a habit strongly associated with recurrence of symptoms. ${ }^{12}$ In the 1970 cohort, children who had wheezed before the age of five years were less likely to wheeze in the past year at age 16 if their mother smoked during pregnancy. This inverse association was not statistically significant but was little altered by adjustment for sex, maternal age, parity, birthweight, and socioeconomic status. ${ }^{10}$ The pooled odds ratio for follow up to age 11 (1958 cohort) or 16 (1970 cohort) is 0.71 (95\% CI
0.57 to $0.89, \chi^{2}$ for heterogeneity $3.58, \mathrm{p}=$ 0.058).

CASE-CONTROL STUDIES: PREVALENCE

Tables 1 and 3 summarise 19 case-control studies $^{21-39}$ relating parental smoking to asthma or wheezing illness after the first year of life. The studies are mostly based on outpatient or inpatient cases, although four ${ }^{29} 353738$ ascertained more severe forms of wheezing illness by a population survey. These papers complement the results of population surveys of diagnosed asthma or symptoms of wheeze reviewed earlier in this series $^{3}$ by addressing more specifically the relationship of parental smoking to the prevalence of more severe forms of asthma, such as might present to hospital clinicians.

The results for either parent smoking (from 14 studies) are summarised in fig 2 . There is borderline significant heterogeneity between studies $\left(\chi^{2}=22.1, \mathrm{df}=13, \mathrm{p}=0.05\right)$, but the size of effect does not appear to be systematically related to the age range studied or to the source of cases or controls. The pooled odds ratio for either parent smoking, derived by random effects modelling, is 1.37 (95\% CI 1.15 to 1.64). Where the effects of maternal and paternal smoking have been compared, there is a consistent finding of an association with smoking by mothers (pooled odds ratio 1.59, 95\% CI 1.27 to 1.99 ), but not with smoking by fathers (pooled odds ratio $0.94,95 \%$ CI 0.78 to 1.12). This contrasts with prevalence surveys of asthma and wheeze among school children in which an effect of smoking by fathers was apparent. ${ }^{3}$

Six of the studies ${ }^{28} 333^{35-37} 39$ present findings before and after adjustment for potential confounding variables. Only one study from Nigeria $^{28}$ reported a substantial reduction in the odds ratio for either parent smoking, from 2.12 to 1.41 after adjustment for pet ownership, indoor mould, cockroaches, wood smoke, and use of mosquito coils. In the remaining five studies the odds ratio for parental smoking was 
Table 3 Unadjusted relative risks associated with parental smoking: case-control studies

\begin{tabular}{|c|c|c|c|c|c|c|c|c|}
\hline \multirow[b]{2}{*}{ Reference } & \multirow[b]{2}{*}{ Age } & \multirow[b]{2}{*}{ Cases } & \multirow[b]{2}{*}{ Controls } & \multicolumn{3}{|c|}{ Odds ratios (95\% CI) for smoking by: } & \multirow[b]{2}{*}{ Dose-response } & \multirow[b]{2}{*}{ Cotinine } \\
\hline & & & & Either parent & Mother & Father & & \\
\hline 21 & $2-16$ & 400 & 213 & $1.30(0.93$ to 1.83$)$ & & & - & - \\
\hline 22 & $1-12$ & 302 & 433 & $1.00(0.70$ to 1.42$)$ & & & Not & - \\
\hline 23 & $0-17$ & 137 & 246 & - & $1.43(0.92$ to 2.23$)$ & $0.71(0.44$ to 1.15$)$ & - & - \\
\hline 24 & $3-15$ & 49 & 77 & $1.97(0.90$ to 4.35$)$ & $2.56(1.23$ to 5.32$)$ & $0.87(0.42$ to 1.80$)$ & Yes & + \\
\hline 25 & $3-14$ & 107 & 121 & $1.13(0.67$ to 1.90$)$ & $2.00(1.16$ to 3.48$)$ & & Yes & + \\
\hline 26 & c. 9 & 102 & 105 & $1.43(0.75$ to 2.71$)$ & & & - & - \\
\hline 27 & $3-4$ & 457 & 457 & - & $1.16(0.89$ to 1.51$)$ & $0.81(0.62$ to 1.06$)$ & - & - \\
\hline 28 & c. 5.5 & 140 & 140 & $2.12(1.32$ to 3.42$)$ & & & - & - \\
\hline 29 & $5-11$ & 115 & 96 & $0.76(0.44$ to 1.31$)$ & & & - & - \\
\hline 30 & $5-7$ & 19 & 43 & $0.71(0.22$ to 2.22$)$ & & & - & + \\
\hline 31 & $3-15$ & 300 & 100 & $0.90(0.57$ to 1.42$)$ & (few smoke) & $0.95(0.60$ to 1.50$)$ & - & - \\
\hline 32 & $0-5$ & 158 & 201 & $1.80(1.20$ to 2.70$)$ & & & - & - \\
\hline 33 & $1.5-4$ & 75 & 137 & $1.46(0.83$ to 2.58$)$ & $1.70(0.93$ to 3.14$)$ & $1.02(0.42$ to 2.46$)$ & No & + \\
\hline 34 & $1-4$ & 193 & 318 & $1.62(1.13$ to 2.32$)$ & & & - & - \\
\hline 35 & $12-18$ & 486 & 475 & - & $1.38(1.18$ to 1.61$)$ & $0.96(0.69$ to 1.34$)$ & Yes & - \\
\hline 36 & $7-12$ & 193 & 149 & $2.00(1.22$ to 3.27$)$ & & & - & + \\
\hline 37 & $7-9$ & 348 & 272 & $1.57(1.06$ to 2.33$)$ & $1.70(1.23$ to 2.34$)$ & $1.23(0.90$ to 1.70$)$ & Yes & + \\
\hline 38 & $6-18$ & 203 & 203 & - & (few smoke) & $1.03(0.63$ to 1.70$)$ & - & - \\
\hline 39 & $4-9$ & 131 & 131 & - & 2.79 (1.66 to 4.67$)$ & - & Yes & - \\
\hline
\end{tabular}

*Urinary cotinine measured (not all such studies reported on dose-response relationships).

†Dose-response relationship only evident for skin prick negative subjects.

altered little by adjustment: from 1.32 to 1.3 after adjustment for family history of asthma and duration of breast feeding in Sweden ${ }^{33}$; from 1.44 to 1.49 after adjustment for age, sex, socioeconomic status, gas cooking, indoor mould, feather bedding, and pet ownership in the $\mathrm{UK}^{35}$; from 1.74 to 1.8 after adjustment for family history of asthma and skin prick positivity to common aeroallergens in the $\mathrm{USA}^{36}$; from 1.97 to 1.87 after adjustment for personal and family history of atopic disease, socioeconomic status, indoor mould, and salt preference in South Africa ${ }^{37}$; and from 2.79 to 2.82 after adjustment for maternal asthma,

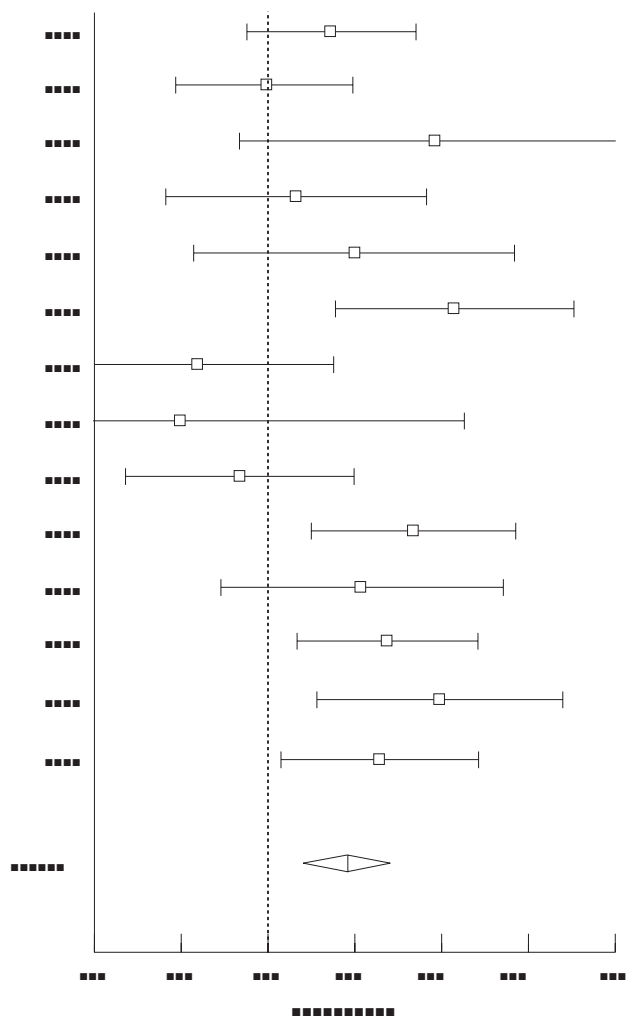

Figure 2 Odds ratios and 95\% confidence intervals for the effect of either parent smoking on prevalence of childhood asthma or wheezing, case-control studies. Pooled odds ratio derived by "random effects" method. history of bronchiolitis, and a range of obstetric and perinatal variables in the USA. ${ }^{39}$

Six studies 242530333637 included measurements of urinary levels of cotinine as an objective marker of tobacco smoke exposure. Generally, the results of questionnaire and biochemical assessment are closely correlated, although one study ${ }^{30}$ found a stronger association of asthma with cotinine levels than with parental smoking assessed by questionnaire. A significant dose-response relationship with cotinine concentration emerges from three studies $^{24}{ }^{25}{ }^{37}$ but not from a fourth. ${ }^{33}$ Two other studies present findings on the relationship between tobacco smoke exposure and the response based on a questionnaire assessment with inconsistent results, ${ }^{22}{ }^{35}$ whereas a third, based on obstetric records, reports a strong exposure-response relationship for daily cigarette consumption by the mother during pregnancy. ${ }^{39}$

Three papers compare the effects of parental smoking at different ages. In the Swedish study by Rylander et $a l^{33}$ the effect of parental smoking was greater at 4-18 months of age (reviewed elsewhere ${ }^{1}$ ) than subsequently. This was so whether exposure was assessed by the number of smoking parents or by urinary cotinine concentration. ${ }^{33}$ An American casecontrol study which measured urinary cotinine levels found a positive association with wheezing before the age of two years, but a non-significant inverse relationship thereafter. ${ }^{41}$ An Italian case-control study compared the effect of parental smoking before and after six years of age. ${ }^{22}$ The odds ratios for either parent smoking were 1.13 (95\% CI 0.71 to 1.80 ) and 0.83 (95\% CI 0.48 to 1.44 ), respectively.

ATOPIC AND NON-ATOPIC WHEEZING

In the British 1958 birth cohort ${ }^{12}$ the increased incidence of asthma or wheezy bronchitis by the age of 16 among children whose mothers smoked during pregnancy was largely concentrated among 3815 subjects with no history of hay fever or eczema (cumulative incidence $24.5 \%$ versus $18.9 \%$, odds ratio $1.39,95 \%$ CI 1.18 to 1.63$)$. Among 1794 subjects reporting 
Table 4 Summary of studies of asthma severity

\begin{tabular}{|c|c|c|c|c|c|c|}
\hline \multirow[b]{2}{*}{ Reference } & \multirow[b]{2}{*}{ Age } & \multirow[b]{2}{*}{ Index of severity } & \multirow[b]{2}{*}{ Index of exposure } & \multicolumn{3}{|c|}{ Association of disease severity with passive smoke exposure: } \\
\hline & & & & Direction & $p$ value & Comments \\
\hline \multicolumn{7}{|l|}{$\begin{array}{l}\text { Population-based case } \\
\text { series: }\end{array}$} \\
\hline 35 & $12-18$ & $\begin{array}{l}\text { Frequency and } \\
\text { intensity }\end{array}$ & Mother smoking & Positive & 0.02 & $\begin{array}{l}\text { Mother smoked in } 34 \%(38 / 113) \text { children with both } \\
\text { frequent and intense attacks and } 23 \%(84 / 373) \text { of less } \\
\text { severe cases }\end{array}$ \\
\hline 36 & $7-12$ & Attack frequency & $\begin{array}{l}\text { Household } \\
\text { smoking }\end{array}$ & Inverse & 0.59 & $\begin{array}{l}35 \%(29 / 82) \text { infrequent wheezers and } 30 \%(20 / 67) \text { with } \\
\geqslant 5 \text { attacks per year were exposed to ETS. Urinary cotinine } \\
\text { levels similar in the two groups }\end{array}$ \\
\hline 37 & $7-9$ & $\begin{array}{l}\text { Frequency and } \\
\text { intensity }\end{array}$ & Mother smoking & Weak +ve & $?$ & $\begin{array}{l}\text { Published odds ratio } 2.04 \text { ( } 1.25 \text { to } 3.34) \text { for severe wheeze } \\
\text { ( } 179 \text { cases) is similar to } 1.87 \text { (1.25 to } 2.81 \text { ) for all wheeze } \\
\text { ( } 325 \text { cases) }\end{array}$ \\
\hline 46 & $0-17$ & $\begin{array}{l}\text { Functional } \\
\text { impairment }\end{array}$ & Mother smoking & Positive & 0.47 & $\begin{array}{l}\text { Functional impairment reported for } 22 \% \text { of asthmatics } \\
\text { whose mothers smoked }(n=144) \text { and } 18 \% \text { of the remaining } \\
\text { asthmatics }(n=128)\end{array}$ \\
\hline 49 & $2-5$ & Asthma medication & Mother smoking & Positive & 0.08 & $\begin{array}{l}\text { Medication taken by } 41 \% \text { of asthmatics whose mother } \\
\text { smoked } \geqslant 10 / \text { day }(n=23) \text { and } 19 \% \text { of other asthmatics } \\
(n=76)\end{array}$ \\
\hline 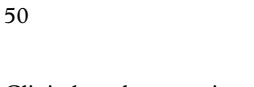 & $0-5$ & Hospitalisations & Mother smoking & No trend & 0.88 & $\begin{array}{l}\text { Mean admission rates } 1.1 \text { per year if mother non-smoker, } \\
1.3 \text { if mother smoked }<10 / \text { day, and } 1.0 \text { per year if mother } \\
\text { smoked } \geqslant 10 / \text { day }\end{array}$ \\
\hline \multicolumn{7}{|l|}{ Clinic-based case series: } \\
\hline 45 & $1-13$ & Composite score & $\begin{array}{l}\text { Household } \\
\text { smoking }\end{array}$ & Positive & 0.15 & $\begin{array}{l}\text { Exposure (mainly to non-maternal smoking) in } 23 \% \\
(43 / 186) \text { mild, } 26 \%(23 / 87) \text { moderate and } 31 \%(33 / 107) \\
\text { severe cases }\end{array}$ \\
\hline 47 & $4-17$ & ER visits per year & $\begin{array}{l}\text { Any ETS } \\
\text { exposure }\end{array}$ & Positive & 0.008 & $\begin{array}{l}\text { Mean } 3.1 \text { visits per year in } 137 \text { smoking homes, } 1.8 \text { per } \\
\text { year in } 122 \text { non-smoking homes }\end{array}$ \\
\hline 48 & $1-17$ & Composite score & Mother smoking & Positive & $<0.01$ & $\begin{array}{l}\text { Severity score related to maternal smoking }(p<0.01) \text { but } \\
\text { not to paternal smoking }(p>0.5)\end{array}$ \\
\hline 51 & $1-17$ & Composite score & Mother smoking & Inverse & $<0.01$ & $\begin{array}{l}\text { Reversal of previous relationship [45] after introduction of } \\
\text { anti-smoking advice (see text) }\end{array}$ \\
\hline 52 & $0-13$ & Attack frequency & Urinary cotinine & Positive & $<0.05$ & $\begin{array}{l}\text { Mean } 3.6 \text { episodes per year if cotinine }>39 \mathrm{ng} / \mathrm{ml}(\mathrm{n}=30) \text {, } \\
2.8 \text { per year if } 10-39 \mathrm{ng} / \mathrm{ml}(\mathrm{n}=53), 2.1 \text { per year if }<10 \\
\mathrm{ng} / \mathrm{ml}(\mathrm{n}=116)\end{array}$ \\
\hline 53 & $5-12$ & Intubation & $\begin{array}{l}\text { Any ETS } \\
\text { exposure }\end{array}$ & Positive & $<0.001$ & $\begin{array}{l}85 \%(11 / 13) \text { intubated patients and } 20 \% \text { of } 287 \\
\text { non-intubated admissions were exposed to ETS (odds ratio } \\
22.4,95 \% \text { CI } 7.4 \text { to } 68.0 \text { ) }\end{array}$ \\
\hline 54 & $1-10$ & Readmission & $\begin{array}{l}\text { Household } \\
\text { smoking }\end{array}$ & Positive & 0.24 & $\begin{array}{l}53 \%(17 / 32) \text { patients readmitted and } 36 \%(13 / 36) \text { children } \\
\text { not readmitted were from smoking homes (odds ratio } 2.01 \text {, } \\
95 \% \text { CI } 0.76 \text { to } 5.30 \text { ) }\end{array}$ \\
\hline
\end{tabular}

ETS $=$ environmental tobacco smoke.

hay fever or eczema at one or more follow up visits, there was little effect of maternal smoking on disease incidence (cumulative incidence $32.2 \%$ versus $33.5 \%$, odds ratio $0.95,95 \%$ CI 0.76 to 1.18 ). This statistical interaction is significant at the $1 \%$ level.

In the Italian case-control study by Palmieri et $a l^{22}$ cases (but not controls) were skin prick tested with six locally relevant aeroallergens. Fewer positive cases were exposed to parental smoking $(77 \%$ versus $82 \%$, odds ratio 0.72 , $95 \%$ CI 0.37 to 1.41 ). The difference was more marked and statistically significant at the 5\% level for exposure to more than 20 cigarettes a day ( $44 \%$ versus $60 \%$, odds ratio $0.54,95 \%$ CI 0.31 to 0.92 ). Among 70 asthmatic children aged under six years in a British outpatient series $^{42}$ smoking by the mother was less common if the serum IgE was raised ( $>1 S D$ above the population mean): $54 \%$ versus $69 \%$, odds ratio $0.54,95 \%$ CI 0.21 to 1.45 . A recent cross sectional survey of Canadian children ${ }^{43}$ has also reported a stronger association of parental smoking with recent asthma among children with no reported history of allergy (odds ratio for current smoking by either parent $2.93,95 \%$ CI 0.83 to 10.3 ) than among children with allergy (odds ratio $0.73,95 \%$ CI 0.37 to 1.46 ). Although these differences are non-significant, they are consistent with the results of the British 1958 birth cohort study, suggesting a stronger association of parental smoking with non-atopic "wheezy bronchitis" than with "allergic asthma".

The opposite conclusion was drawn from a study of allergy clinic patients aged 1-17 years in Vancouver. ${ }^{44}$ Among 224 patients with atopic dermatitis, maternal smoking was associated with an increased risk of diagnosed asthma (odds ratio 3.42 , 95\% CI 1.60-7.30) whereas among 396 patients without atopic dermatitis there was no association (odds ratio $0.93,95 \%$ CI 0.57 to 1.51 ). This interaction is statistically significant at the $1 \%$ level, but the findings are difficult to interpret biologically without consideration of possible referral biases in this clinic based study.

SEVERITY

There are several dimensions to the severity of an episodic disease such as asthma: frequency of wheezing episodes, persistence of symptoms between "attacks", occurrence of clinically severe or life threatening bronchospasm, need for preventer and/or reliever medications, use of health services, and interference with daily activities. We identified three case-control studies $^{35-37}$ and 10 uncontrolled case series ${ }^{45-54}$ which present data on asthma severity in relation to parental smoking. Various dimensions of severity have been used and some studies have combined a number of indices into a composite "severity score". ${ }^{45} 481$

Due to the different approaches employed in each study, no formal meta-analysis is possible, 
but a qualitative review is presented in table 4 . This suggests greater disease severity in children exposed to smoking in the household, a pattern which is more consistent among asthmatics attending hospital as outpatients or inpatients than among cases identified through population surveys.

Few of these studies have adjusted for potential confounding variables, and it is possible that some of the associations of parental smoking with health service utilisation, in particular, may reflect a common association with lower socioeconomic status. On the other hand, the striking association of passive smoke exposure with near-fatal asthma, evaluated retrospectively in a tertiary medical care centre in California, ${ }^{53}$ was stronger than a range of psychosocial variables, suggesting that it would not be entirely explained by socioeconomic confounding. However, a mutually adjusted analysis was not possible as only two of the 13 patients requiring intubation came from nonsmoking households.

EFFECT OF REDUCING TOBACCO SMOKE EXPOSURE

The early case-control study by O'Connell and $\operatorname{Logan}^{21}$ reported that $67 \%$ of the 265 cases who were exposed to parental smoking considered that it aggravated their symptoms, and tobacco smoke exposure was considered a "significant factor" in $10 \%$ of children (16/ 158) where one parent smoked, and in $20 \%$ (21/107) where both parents smoked. These 37 children were included in an empirical study of anti-smoking advice and 35 were followed up 6-24 months later. Symptoms had improved in $90 \%$ of children $(18 / 20)$ whose parents had stopped smoking, and in $27 \%$ of children (4/15) who remained passively exposed to tobacco smoke. These results are promising but difficult to interpret because this is an uncontrolled "on treatment" analysis and not a randomised controlled trial analysed by "intention to treat".

A composite score was used to grade severity among 415 children aged 1-17 years attending an allergy clinic in Vancouver with a diagnosis of asthma during $1983-86 .{ }^{48}$ The severity score was significantly higher among children of smoking mothers $(p<0.01)$, but when the analysis was repeated for an additional 387 subjects attending the same clinic during $1986-90,{ }^{51}$ the relationship between maternal smoking and asthma severity score had reversed. This was due to a highly significant $(p<0.001)$ decline in the severity of asthma in the children of smoking mothers, and little change in severity for children whose mothers did not smoke. The authors attribute this change to an alteration in parental smoking habits following advice from clinicians to avoid smoking in the home or in the presence of the child. However, this is based on anecdotal reports and no objective data are presented to confirm the postulated reduction in personal exposure of the children.

\section{Discussion}

The results summarised here and in previous reviews ${ }^{13}$ present a complex picture of the associations of parental smoking with asthma incidence, prognosis, prevalence, and severity. The incidence and recurrence of wheezing illness in early life is increased if there is smoking in the household, particularly by the mother ${ }^{1}$ (table 2), whereas the incidence of asthma during the school years is less strongly affected by parental smoking. A similar agerelated decline in the strength of the passive smoking effect is evident in cross sectional studies. ${ }^{3}$ This may simply reflect the diminishing level of exposure to environmental tobacco smoke from household sources as children grow up..$^{55}$ Alternatively or additionally, parental smoking may have differential effects on the incidence of various forms of wheezing illness ${ }^{56}$ with a stronger influence on viral associated wheezing (common in early childhood) and a weaker relationship with atopic wheezing (often of later onset). Four studies comparing wheezing in atopic and non-atopic children lend support to the latter hypothesis, ${ }^{1224243}$ although a fifth does not. ${ }^{44}$

In our previous review of lower respiratory illnesses in infancy there was evidence of adverse effects from postnatal exposure to smoking by the father in households where the mother did not smoke, but insufficient evidence to distinguish the separate effects of prenatal and postnatal smoking by the mother. ${ }^{1}$ Although several of the longitudinal studies reviewed here reported findings in relation to maternal smoking in pregnancy, this reflects the information available and does not necessarily imply that prenatal exposure is especially important. Unfortunately, there are insufficient published data to assess the isolated effect of non-maternal smoking on the incidence or natural history of childhood asthma after the first few years of life. Whereas most longitudinal studies show a weak association between the incidence of asthma and paternal smoking, this could be partially due to confounding by maternal smoking. In case-control studies maternal smoking appeared to be the dominant influence, with little effect from smoking by the father.

Although wheezing in infancy is more likely to recur if the parents smoke, maternal smoking, at least, is associated with a relatively benign long term prognosis (table 2). This could also reflect a stronger association of parental smoking with non-atopic wheezing ("wheezy bronchitis" rather than "allergic asthma") which is associated with a better prognosis. On the other hand, atopic children tend to have more severe, frequent or persistent wheezing, and case-control studies of more severe ("clinic") asthmatics show a positive association, with maternal smoking again appearing of greater importance. Indeed, the pooled odds ratio for either parent smoking from these case-control studies (1.37) is somewhat greater than the corresponding pooled odds ratios from cross sectional surveys of wheezing (1.24) and asthma (1.21) among school children. ${ }^{3}$ Furthermore, among asth- 
matic children, most studies have found greater severity of disease if the parents smoke (table 4 ), and prevalence surveys among schoolchildren suggest a stronger association with more restrictive (presumably more severe) definitions of wheeze than with any recent wheeze. ${ }^{3}$

Thus, we are faced with a paradox: studies of incidence and prognosis suggest an association of parental smoking primarily with early non-atopic wheezing which tends to run a mild and transient course, whereas studies of prevalence and severity suggest that exposure to environmental tobacco smoke increases the risk of more severe symptoms, outpatient clinic attendance, or emergency hospital admission. One solution to this apparent paradox would be to consider environmental tobacco smoke as a co-factor operating with intercurrent infections as a trigger of wheezing attacks, rather than as a factor initiating or inducing the asthmatic state. This distinction between induction (initiation) and exacerbation (provocation) also emerges when considering the role of outdoor air pollution as a cause of asthma. ${ }^{57}$

The incidence of both wheezing and nonwheezing lower respiratory illnesses in infancy are increased to a similar extent if the parents smoke, due at least in part to postnatal (environmental) exposure. ${ }^{1}$ It is likely that the clinical severity of viral respiratory infections in older children is also exacerbated by passive smoke exposure leading to an increased risk of respiratory symptoms in general, ${ }^{3}$ including wheeze. Among children at low risk of wheezing, passive smoke exposure at times of intercurrent infection may be sufficient to cause occasional episodes of asthmatic symptoms and thus increase the risk of a mild, often transient wheezing tendency which the child outgrows as the airways become larger or less reactive with increasing age.

Previous reviews have concluded that passive smoking is causally associated with increased incidence and severity of asthma ${ }^{58}{ }^{59}$ and have attributed this to chronic, but possibly reversible, effects of parental smoking on bronchial hyperreactivity rather than to acute effects of cigarette smoke on airway calibre. ${ }^{58}$ Our assessment concurs so far as the health effects are concerned, but implies a different mechanism.

If the principal effect of passive smoking is to increase the probability of lower respiratory symptoms during viral respiratory infection, we would predict that it would be associated more strongly and consistently with acute manifestations of asthma than with long term indicators of the asthmatic tendency such as non-specific bronchial responsiveness. This review has shown that measures of disease severity such as the frequency of wheezing episodes or the incidence of intense or life-threatening attacks, which relate to acute exacerbations of existing asthma, are associated with household exposure to tobacco smoke. A later review in this series will examine the relationship between parental smoking and objective measures of bronchial hyperreactivity.
This review was commissioned by the Department of Health. The views expressed are those of the authors and not necessarily those of the Department of Health. We are indebted to Jenny Taylor and Claire Chazot for their diligent compilation of the available literature.

1 Strachan DP, Cook DG. Health effects of passive smoking: 1-Parental smoking and lower respiratory illness in infancy and early childhood. Thorax 1997;52:905-14.

2 Strachan DP, Cook DG. Health effects of passive smoking: 5-Parental smoking and allergic sensitisation in children. Thorax 1998;53 (in press).

3 Cook DG, Strachan DP. Health effects of passive smoking: 3 -Parental smoking and prevalence of respiratory symp-
toms and asthma in school age children. Thorax 1997;52: 1081-94.

4 Fergusson DM, Horwood LJ. Parental smoking and respiratory illness during early childhood: a six-year longitudinal study. Pediatr Pulmonol 1985;1:99-106.

5 Horwood LJ, Fergusson DM, Shannon FT. Social and familial factors in the development of early childhood asthma. Pediatrics 1985;75:859-68.

6 Neuspiel DR, Rush D, Butler NR, et al. Parental smoking and post-infancy wheezing in children: a prospective and post-infancy wheezing in children: a prospe

7 Martinez FD, Cline M, Burrows B. Increased incidence of Martinez FD, Cline M, Burrows B. Increased incidence of
asthma in children of smoking mothers. Pediatrics 1992;89: asthma

8 Sherman CB, Tosteson TD, Tager IB, et al. Early childhood predictors of asthma. Am f Epidemiol 1990;132:83-95.

9 Martinez FD, Wright AL, Taussig LM, et al. Asthma and wheezing in the first six years of life. The Group Health Medical Associates. N Engl f Med 1995;332:133-8.

10 Lewis S, Richards D, Bynner J, et al. Prospective study of risk factors for early and persistent wheezing in childhood. Eur Respir ₹ 1995;8:349-56.

11 Taylor B, Wadsworth J, Golding J, et al. Breast feeding, eczema, asthma, and hayfever. $\mathcal{f}$ Epidemiol Community Health 1983;37:95-9.

12 Strachan DP, Butland BK, Anderson HR. The incidence and prognosis of asthma and wheezing illness from early childhood to age 33 in a national British cohort. BMF 1996;312:1195-9.

13 Anderson HR, Bland JM, Peckham C. The natural history of asthma in childhood. $\mathcal{f}$ Epidemiol Community Health 1986;40:121-9.

14 Holberg CJ, Wright AL, Martinez FD, et al. Child day care, smoking by caregivers, and lower respiratory tract illness in the first 3 years of life. Group Health Medical Associates. Pediatrics 1993;91:885-92.

15 McConnochie KM, Roghmann KJ. Bronchiolitis as a possible cause of wheezing in childhood: new evidence. Pediatrics 1984;74:1-10.

16 Welliver RC, Wong DT, Sun M, et al. Parainfluenza virus bronchiolitis: epidemiology and pathogenesis. Am $\mathcal{F}$ Dis Child 1986;140:34-40.

17 Geller-Bernstein G, Kenett R, Weisglass L, et al. Atopic babies with wheezy bronchitis. Follow-up study relating prognosis to sequential IgE values, type of early infant feeding, exposure to parental smoking and incidence of feeding, exposure to parental smoking and incidence of
lower respiratory tract infections. Allergy 1987;42:85-91.

18 Toyoshima K, Hayashida M, Yasunami J, et al. Factors influencing the prognosis of wheezy infants. $\dot{f}$ Asthma influencing the pros

19 Rylander E, Eriksson M, Freyschuss U. Risk factors for occasional and recurrent wheezing after RSV infection in infancy. Acta Paediatr Scand 1988;77:711-5.

20 Strachan DP. Epidemiology. In: Silverman M, ed. Childhood asthma and other wheezing disorders. London: Chapman \& Hall, 1995: 7-31.

21 O'Connell EJ, Logan GB. Parental smoking in childhood asthma. Ann Allergy 1974;32:142-5.

22 Palmieri M, Longobardi G, Napolitano G, et al. Parental smoking and asthma in childhood. Eur f Pediatr 1990;149: $738-40$

23 Daigler GE, Markello SJ, Cummings KM. The effect of indoor air pollutants on otitis media and asthma in children. Laryngoscope 1991;101:293-6.

24 Willers S, Svenonius E, Skarping G. Passive smoking and childhood asthma. Urinary cotinine levels in children with asthma and in referents. Allergy 1991;46:330-4.

25 Ehrlich R, Kattan M, Godbold J, et al. Childhood asthma and passive smoking. Urinary cotinine as a biomarker of and passive smoking. Urinary cotinine as a b

26 Butz AM, Rosenstein BJ. Passive smoking among children with chronic respiratory disease. F Asthma 1992;29:2652

27 Infante-Rivard C. Childhood asthma and indoor environmental risk factors. Am f Epidemiol 1993;137:834-44.

28 Fagbule D, Ekanem EE. Some environmental risk factors for childhood asthma: a case-control study. Ann Tropical Paediatr 1994;14:15-9.

29 Leen MG, O'Connor T, Kelleher C, et al. Home environment and childhood asthma. Irish Med f 1994;87: $142-4$.

30 Clark SJ, Warner JO, Dean TP. Passive smoking amongst asthmatic children. Questionnaire or objective assessment? Clin Exp Allergy 1994;24:276-80.

31 Mumcuoglu KY, Abed Y, Armenios B, et al. Asthma in Gaza refugee camp children and its relationship with house dust refugee camp children and its rela
mites. Ann Allergy 1994;72:163-6.

32 Azizi BH, Zulkifli HI, Kasim S. Indoor air pollution and asthma in hospitalized children in a tropical environment. $\mathcal{F}$ Asthma 1995;32:413-8. 
33 Rylander E, Pershagen G, Eriksson M, et al. Parental smoking urinary cotinine, and wheezing bronchitis in children. ing, urinary cotinine, and whe

34 Lindfors A, Wickman M, Hedlin G, et al. Indoor environmental risk factors in young asthmatics: A casecontrol study. Arch Dis Child 1995;73:408-12.

35 Strachan DP, Carey IM. Home environment and severe asthma in adolescence: a population based case-control study. BMF 1995;311:1053-6.

36 Henderson FW, Henry MM, Ivins SS, et al. Correlates of recurrent wheezing in school-age children. The Physicians of Raleigh Pediatric Associates. Am 7 Respir Crit Care Med 1995;151:1786-93.

37 Ehrlich RI, Du Toit D, Jordaan E, et al. Risk factors for childhood asthma and wheezing. Importance of maternal and household smoking. Am f Respir Crit Care Med 1996;154:681-8.

38 Moussa MA, Skaik MB, Yaghy OY, et al. Factors associated with asthma in school children. Eur $\mathcal{F}$ Epidemiol 1996;12: with as 58 .

39 Oliveti JF, Kercsmar CM, Redline S. Pre- and postnatal risk factors for asthma in inner city African-American children. factors for asthma in inner city Afric

40 Rylander E, Pershagen G, Eriksson M, et al. Parental smoking and other risk factors for wheezing bronchitis in children. Eur f Epidemiol 1993;9:517-26.

41 Duff AL, Pomeranz ES, Gelber LE, et al. Risk factors for acute wheezing in infants and children: viruses, passive smoke, and IgE antibodies to inhalant allergens. Pediatrics 1993;92:535-40.

42 Kershaw CR. Passive smoking, potential atopy and asthma in the first five years. $7 R$ Soc Med 1987;80:683-8.

43 Chen Y, Rennie DC, Dosman JA. Influence of environmental tobacco smoke on asthma in nonallergic and allergic children. Epidemiology 1996;7:536-9.

44 Murray AB, Morrison BJ. It is children with atopic dermatitis who develop asthma more frequently if the mother tis who develop asthma more frequently if the

45 Aderele WI. Aetiologic, precipitating and environmental factors in childhood asthma. Nigerian $\mathcal{f}$ Paediatr 1982;9: factors

46 Gortmaker SL, Walker DK, Jacobs FH, et al. Parental smoking and the risk of childhood asthma. Am $\mathcal{F}$ Public Health 1982;72:574-9.
47 Evans D, Levison MJ, Feldman $\mathrm{CH}$, et al. The impact of passive smoking on emergency room visits of urban children with asthma. Am Rev Respir Dis 1987;135: $567-72$.

48 Murray AB, Morrison BJ. Passive smoking by asthmatics: its greater effect on boys than on girls and on older than on younger children. Pediatrics 1989;84:451-9.

49 Weitzman M, Gortmaker S, Sobol A Racial, social, and environmental risks for childhood asthma. Am 7 Dis Child 1990;144:1189-94.

50 Weitzman M, Gortmaker S, Walker DK, et al. Maternal smoking and childhood asthma. Pediatrics 1990;85:505-11.

51 Murray AB, Morrison BJ. The decrease in severity of asthma in children of parents who smoke since the parents have been exposing them to less cigarette smoke. F Allergy Clin Immunol 1993;91:102-10.

52 Chilmonczyk BA, Salmun LM, Megathlin $\mathrm{KN}$, et al. Association between exposure to environmental tobacco smoke and exacerbations of asthma in children. $N$ Engl $\mathcal{F}$ Med 1993;328:1665-9.

53 LeSon S, Gershwin ME. Risk factors for asthmatic patients requiring intubation. I. Observations in children. $\mathcal{F}$ Asthma 1995;32:285-94.

54 Macarthur C, Calpin C, Parkin PC, et al. Factors associated with pediatric asthma readmissions. F Allergy Clin Immunol 1996;98:992-3.

55 Irvine L, Crombie IK, Clark RA, et al. What determines levels of passive smoking in children with asthma? Thorax 1997;52:766-9.

56 Wilson NM. Wheezy bronchitis revisited. Arch Dis Child 1989;64:1194-9.

57 Department of Health Committee on the Medical Effects of Air Pollutants. Asthma and outdoor air pollution. London: HMSO, 1995: 85-176.

58 US Department of Health and Human Services, US Environmental Protection Agency. Respiratory health effects of passive smoking: lung cancer and other disorders. NIH publication no. 93-3605, August 1993: 230-49.

59 Halken S, Host A, Nilsson L, et al. Passive smoking as a risk factor for development of obstructive respiratory disease and allergic sensitization. Allergy 1995;50:97-105. 